\title{
Incidence and Risk Factors Associated with Retinopathy of Prematurity in Peru
}

\section{Carmen Sarita Carranza- Mendizabal ${ }^{1,2}$ \\ Mariela Diaz-Manrique ${ }^{1,2}$ \\ Percy G Ruiz Mamani ${ }^{3}$ \\ Michael White (D) ${ }^{4}$ \\ Salomon Huancahuire- Vega $\left(\mathbb{D}^{2,4}\right.$}

'Ophthalmology Service, Hipólito Unanue National Hospital, Lima, Peru; ${ }^{2}$ Human Medicine School, Peruvian Union University (UPeU), Lima, Peru; ${ }^{3}$ San Juan Bautista Private University, Lima, Peru; ${ }^{4}$ Directorate General Research, Peruvian Union University (UPeU), Lima, Peru
Correspondence: Salomon HuancahuireVega

Human Medicine School, Peruvian Union University (UPeU), Carretera Central Km 19 Ñaña Lurigancho-Chosica, Lima 15, Lima, Peru

Tel +5I-9975740I I

Email salomonhuancahuire@upeu.edu.pe
Purpose: The purpose of this research is to determine retinopathy of prematurity (ROP) prevalence and possible risk factors associated with ROP development in newborns admitted to a neonatal unit of a Peruvian National Reference Hospital.

Patients and Methods: This retrospective study included 216 preterm infants. The data were collected between January 2016 and December 2018. All infants were examined according to Peruvian guidelines for screening and treatment of ROP. The association of clinical risk factors and the development of ROP was analyzed and predictive factors were determined.

Results: The study subjects were 216 preterm infants of which 72 had some stage of ROP (32 stage 1; 23 stage 2 and 17 stage 3) and 144 preterm infants without ROP. The incidence of ROP in preterm infants less than 32 weeks was $60.9 \%$, while for those weighing less than $1500 \mathrm{~g}$ it was $71.6 \%$. The factors associated with ROP were gestational age below 32 weeks, birth weight below 1500 grams, neonatal sepsis, oxygen therapy, mechanical ventilation, hyaline membrane disease, bronchopulmonary dysplasia, persistence of ductus arteriosus and intraventricular hemorrhage. Exclusive breastfeeding was found to play a protective role against ROP. Binary logistic regression analysis found that only gestational age below 32 weeks (OR, 2.637; 95\% CI, 1.04-6.69), weight below 1500 grams (OR, 4.377; 95\% CI, 1.75-10.92), neonatal sepsis (OR, 6.517; 95\% CI, 2.81-15.14), vaginal delivery (OR, 3.748; 95\% CI: 1.54-9.14), and the presence of hyaline membrane disease (OR, 3.58; 95\% CI, $1.47-8.74)$ are predictors of ROP.

Conclusion: The incidence of ROP among very low birth weight infants was $71.6 \%$. Infants with weight below 1500 grams, neonatal sepsis, presence of hyaline membrane disease whose mother had vaginal delivery are at risk for the development of ROP. Thus, preventing premature births and encouraging exclusive breastfeeding are two main ways to prevent ROP.

Keywords: retinopathy of prematurity, gestational age, sepsis, birth weight, anemia, exclusive breastfeeding

\section{Introduction}

The incidence of premature births worldwide in 2014 was about 15 million, a rate that has been increasing over the past 20 years. ${ }^{1}$ It is estimated that one in ten newborns is born prematurely worldwide, more than 1 million children die each year from complications of premature birth, and many survivors face a lifetime of disabilities, including learning disabilities, hearing disabilities, and visual impairments. ${ }^{2}$

One of its main complications is retinopathy of prematurity (ROP), a vasoproliferative developmental disorder of the retinal vessels that affects preterm 
infants and, if left untreated, can lead to severe and irreversible visual impairment. ${ }^{3}$ Although significant progress has been made in perinatal care, ROP remains a serious complication. It is estimated that each year about 170,000 preterm infants worldwide develop some degree of ROP, of which 20,000 end in severe visual impairment or secondary blindness. ${ }^{4}$ In Latin America, the prevalence of ROP at some stage varies from $6.6 \%$ to $82 \%$ while the most severe stage is in the range of $1.2 \%$ to $25 \%{ }^{5}$ In Peru, there is little information on incidence and risk factors of ROP. ${ }^{6}$ Although significant progress has been made in perinatal care, the country still lacks strategies for proper diagnosis and treatment, which increases the likelihood of poor prognosis and inadequate management, making ROP a serious complication in premature infants. ${ }^{5}$

Multiple studies show that ROP is a multifactorial pathology; among the neonatal risk factors that have been described are low birth weight, gestational age, neonatal sepsis, respiratory distress, hyaline membrane disease, transient tachypnea, bronchopulmonary dysplasia, oxygen therapy, mechanical ventilation, intraventricular hemorrhage, anemia and persistence of the ductus arteriosus. $^{7-9}$ Identification of risk factors involved in the progression of ROP and a better understanding of their etiology can help ophthalmologists and neonatologists in careful detection, accurate diagnosis and prevention of disease development. ${ }^{9}$ Retinopathy of prematurity is generally predictable in nature, sequentially progressive, such that timely treatment has been shown to reduce the risk of visual loss, and effective care with carefully timed indirect ophthalmoscopy examinations to identify the presence of ROP allows for timely treatment. ${ }^{10}$

This article determines the incidence of ROP and evaluates the possible risk factors associated with the development of ROP in newborns admitted to a neonatal unit of a Peruvian level III hospital.

\section{Methods}

\section{Design}

This was a retrospective case-control study in which the medical records of all preterm infants admitted to the neonatal unit of the Hipólito Unanue National Hospital from January, 2016 to December, 2018 were reviewed. This is a level III-1 hospital belonging to the Ministry of Health which serves the population of Eastern Lima. The project was approved by the Ethics Committee of the Hospital.

\section{Participants and Procedure}

During the 3-year study period, 300 preterm infants were admitted to the neonatal area, of which 216 met the inclusion criteria: gestational age $<37$ weeks (obtained by the Capurro method), ${ }^{11}$ birth weight $<2500 \mathrm{~g}$, indirect ophthalmoscopy by the ophthalmology specialist, and 84 were excluded due to death before the first month of life, failure to complete screening for ROP, multiple pregnancies, congenital malformation, or incomplete data in their medical history.

The variables included in the study were selected based on Peruvian guidelines for screening and treatment of ROP. These guidelines were prepared to establish the dispositions for preterm infant care with high risk of ROP in Peruvian hospitals and the screening needed to identify ROP for early treatment. It also evaluates maternal and neonatal risk for ROP. ${ }^{12}$ Data were collected for gender, gestational age, birth weight, occurrence of anemia, occurrence of sepsis (based on clinical assessment and positive blood cultures), type of breastfeeding, oxygen therapy, mechanical ventilation, type of delivery, and presence of systemic comorbidities such as lung disease (hyaline membrane disease, bronchopulmonary dysplasia, transient tachypnea of the newborn, all diagnosed by physical examination and auxiliary tests such as X-rays or CT scans), digestive disease (necrotizing enterocolitis), and heart disease (persistence of ductus arteriosus, intraventricular hemorrhage). Based on the results of other studies, each preterm infant was assigned a category based on gestational age ( $\leq 32$ weeks and $>32$ weeks) and birth weight $(\leq 1500$ $\mathrm{g}$ and $>1500 \mathrm{~g}$ ) because these studies found that these two cutoff points show a significant association with the development of ROP. ${ }^{13,14}$

\section{Statistical Analysis}

The statistical analyses were carried out with the $\mathrm{R}$ and SPSS programs. A bivariate analysis was made using chisquared to identify possible factors associated with ROP, in addition the OR was calculated. To identify the predictors of ROP, a multivariate analysis was done. Factors that were significantly associated with ROP $(\mathrm{p}<0.05)$ were included in a binary logistic regression model and the gradual backward elimination method was applied, considering a significance level of 0.10 .

\section{Results}

Information was initially collected from 300 preterm infants, of which 84 cases (28\%) were excluded (Figure 1). Of these, 12 did not survive the first month 


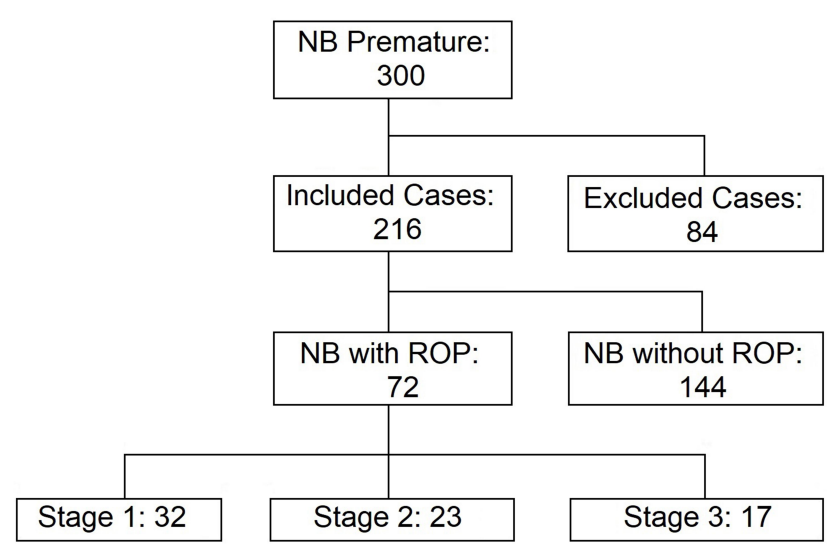

Figure I Diagram of the distribution of preterm infants in the study. Abbreviations: NB, newborns; ROP, retinopathy of prematurity.

of life and therefore did not complete the ophthalmological examination (4\%), 46 were from a multiple pregnancy (15\%), 4 had congenital malformations (1.3\%) and 22 recorded incomplete data (7.3\%). Thus, 216 preterm infants were considered in the study; 94 were female (43.5\%) and 122 male (56.5\%). As for their clinical characteristics, $87(40.3 \%)$ were born before 32 weeks of gestation, 67 (31\%) weighed less than 1500 grams, 18 $(8.3 \%)$ were diagnosed with anemia, 78 (36.1\%) presented sepsis, $187(86 \%)$ received mixed or non-exclusive breastfeeding, 158 (73.1\%) received oxygen therapy, 73 (33.8\%) were breathing through mechanical ventilators, 77 (35.6\%) were born through vaginal delivery, 102 (47.2\%) had hyaline membrane disease (Table 1).

Out of all the infants who received an ophthalmological evaluation by specialists, 72 (33\%.3) were diagnosed with ROP in any stage; 32 were in stage $1(44.4 \%), 23$ in stage $2(31.9 \%)$ and 17 in stage $3(23.6 \%)$; however, it is noteworthy that in the three stages there are greater frequencies in the area of affectation III located in both eyes (Table 2). No cases were found with affectation in Zone I, since this zone is the one close to the papilla and the optic nerve, meaning that an affectation in this area would be of greater severity. Likewise, stage 3 lesions were not evidenced in the I and II areas, since this stage implies extraretinal fibrovascular proliferation, and I and II zones are more concentric.

The incidence of ROP in preterm infants under 32 weeks was $60.9 \%$ (53 of 87 ), while for those weighing less than 1500 grams it was $71.6 \%$ (48 of 67 ). Bivariate statistical analysis (Table 3) shows that ROP is significantly $(\mathrm{p}<0.01)$ associated with gestational age below 32 weeks $(\mathrm{OR}=9.02)$, birth weight below 1500 grams
$(\mathrm{OR}=13.15)$, neonatal sepsis $(\mathrm{OR}=15.0)$, oxygen therapy $(\mathrm{OR}=10.2)$, mechanical ventilation $(\mathrm{OR}=6.232)$, hyaline membrane disease $(\mathrm{OR}=12.14)$, bronchopulmonary dysplasia $(\mathrm{OR}=3.36)$, ductus arteriosus persistence $(\mathrm{OR}=4.14)$ and intraventricular hemorrhage $(\mathrm{OR}=$ 15.40). Significant associations were also found $(\mathrm{p}<$ $0.05)$ with hemoglobin level below $13.5 \mathrm{mg} / \mathrm{dL}(\mathrm{OR}=$ $2.74)$ and vaginal delivery $(\mathrm{OR}=2.10)$. Only 4 preterm infants were exclusively breastfed and had ROP, this association was significant $(\mathrm{p}<0.05)$; therefore, this analysis suggests that exclusive breastfeeding plays a protective role against $\mathrm{ROP}(\mathrm{OR}=0.28)$. A similar result was obtained with transient tachypnea of the newborn $(\mathrm{OR}=$ 0.183 ).

The multivariate analysis was performed with the variables that were significantly $(\mathrm{p}<0.05)$ associated with ROP (Table 4). Thus, we found that gestational age less than 32 weeks $(\mathrm{ORB}=2.63)$, weight less than 1500 grams $(\mathrm{ORB}=4.37)$, neonatal sepsis $(\mathrm{ORB}=6.51)$, vaginal delivery $(\mathrm{ORB}=3.74)$, and the presence of hyaline membrane disease $(\mathrm{ORB}=7.83)$ are predictors of ROP $(\mathrm{p}$ $<0.05)$.

\section{Discussion}

ROP continues to be one of the leading causes of childhood blindness in the world, and in Peru it is the leading cause. ${ }^{15}$ This is due to the increased survival rate of very premature infants with the development of neonatal intensive care units.

The incidence of ROP varies considerably in different populations and ethnic groups, so much so that in India it fluctuates from 38 to $47 \%$, Thailand reports prevalence between 14 and 33\%, while in Mexico approximately $24 \%$ of childhood blindness occurs as a result of ROP. ${ }^{16}$ In this study, the overall incidence of ROP in preterm infants was $33.3 \%$ (72 of 144), with $23.6 \%$ of these infants having severe ROP (stage 3) (Tables 2 and 3). In a study conducted in 2010-2011 in the same city, an incidence of $19.06 \%$ was reported, ${ }^{17}$ this increase in recent years is also evident in other Latin American countries. ${ }^{5}$

In this retrospective study, we analyzed the risk factors associated with ROP. It is noteworthy that the incidence and severity of ROP is inversely related to gestational age and birth weight. ${ }^{3}$ This study showed that newborns with gestational age $\leq 32$ weeks had 9.02 times $(p<0.001)$ more risk of presenting ROP (Table 3), on the other hand, newborns with a weight $\leq$ to $1500 \mathrm{gr}$. had a 13.15 times higher risk $(\mathrm{p}<0.001)$. These results are consistent with other 
Table I Distribution of Clinical Characteristics of Preterm Infants

\begin{tabular}{|c|c|c|c|c|}
\hline \multirow[t]{2}{*}{ Variables } & \multirow[t]{2}{*}{ Values } & Female (94) & Male (1 22) & Total (216) \\
\hline & & n (\%) & n (\%) & n (\%) \\
\hline \multirow[t]{2}{*}{ Gestational age } & $<32$ weeks & $43(45.7)$ & $44(36.1)$ & $87(40.3)$ \\
\hline & $>32$ weeks & $5 I(54.3)$ & $78(63.9)$ & $129(59.7)$ \\
\hline \multirow[t]{2}{*}{ Weight } & $<1500 \mathrm{gr}$ & $33(35.1)$ & $34(27.9)$ & $67(3 \mathrm{I})$ \\
\hline & $>1500 \mathrm{gr}$ & $61(64.9)$ & $88(72.1)$ & 149 (69) \\
\hline \multirow[t]{2}{*}{ Anemia } & $\mathrm{Hb}<13.0 \mathrm{mg} / \mathrm{dl}$ & $9(9.6)$ & $9(7.4)$ & $18(8.3)$ \\
\hline & $\mathrm{Hb}>13.0 \mathrm{mg} / \mathrm{dl}$ & $85(90.4)$ & $113(92.6)$ & $198(91.7)$ \\
\hline \multirow[t]{2}{*}{ Sepsis } & Yes & $36(38.3)$ & $42(34.4)$ & $78(36.1)$ \\
\hline & No & $58(61.7)$ & $80(65.6)$ & $138(63.9)$ \\
\hline \multirow[t]{2}{*}{ Breastfeeding } & Exclusive & $10(10.6)$ & $19(15.6)$ & $29(13.4)$ \\
\hline & Mixed & $84(89.4)$ & $103(84.4)$ & $187(86.6)$ \\
\hline \multirow[t]{2}{*}{ Oxygen therapy } & Yes & $66(70.2)$ & $92(75.4)$ & I58 (73.1) \\
\hline & No & $28(29.8)$ & $30(24.6)$ & $58(26.9)$ \\
\hline \multirow[t]{2}{*}{ Mechanical Ventilation } & Yes & $34(36.2)$ & $39(32)$ & $73(33.8)$ \\
\hline & No & $60(63.8)$ & $83(68)$ & $143(66.2)$ \\
\hline \multirow[t]{2}{*}{ Type of delivery } & Vaginal & $32(34)$ & $45(36.9)$ & 77 (35.6) \\
\hline & Cesarean section & $62(66)$ & $77(63.1)$ & $139(64.4)$ \\
\hline \multirow[t]{2}{*}{ Hyaline Membrane Disease } & Yes & $39(4 \mid .5)$ & $63(51.6)$ & $102(47.2)$ \\
\hline & No & $55(58.5)$ & $59(48.4)$ & $114(52.8)$ \\
\hline \multirow[t]{2}{*}{ Transient tachypnea of the newborn } & Yes & $16(17)$ & $23(18.9)$ & $39(18.1)$ \\
\hline & No & $78(83)$ & $99(8 \mathrm{I} .1)$ & $177(8 \mid .9)$ \\
\hline \multirow[t]{2}{*}{ Bronchopulmonary dysplasia } & Yes & $3(3.2)$ & $8(6.6)$ & II (5.I) \\
\hline & No & 91 (96.8) & $114(93.4)$ & $205(94.9)$ \\
\hline \multirow[t]{2}{*}{ Necrotizing Enterocolitis } & Yes & $4(4.3)$ & I (0.8) & $5(2.3)$ \\
\hline & No & $90(95.7)$ & I2I (99.2) & $211(97.7)$ \\
\hline \multirow[t]{2}{*}{ Ductus arteriosus persistence } & Yes & $15(16)$ & $12(9.8)$ & $27(12.5)$ \\
\hline & No & $79(84)$ & $110(90.2)$ & $189(87.5)$ \\
\hline \multirow[t]{2}{*}{ Intraventricular hemorrhage } & Yes & $2(2.1)$ & $6(4.9)$ & $8(3.7)$ \\
\hline & No & $92(97.9)$ & II $6(95.1)$ & $208(96.3)$ \\
\hline
\end{tabular}

Abbreviation: $\mathrm{Hb}$, hemoglobin.

studies that have reported these factors among those most associated with ROP. ${ }^{13}$ Additionally, in multivariate analysis, both factors were found to predict ROP in preterm infants (Table 4).
Pre-term infants with intraventricular hemorrhage and sepsis were 15 times $(\mathrm{p}<0.001)$ more likely to have ROP, so both variables would be the most prominent risk factors. Sepsis in this case is referred to as early-onset, 
Table 2 Distribution of Preterm Infants with Retinopathy According to Location, Stage and Area of Involvement. The Stages Were Classified According to the International Classification of ROP

\begin{tabular}{|l|c|c|c|c|}
\hline Stage & Affected Area & Location & N & $\%$ \\
\hline I & II & BE & 4 & $5.60 \%$ \\
I & II & LE & 2 & $2.80 \%$ \\
I & III & LE & 3 & $4.20 \%$ \\
I & III & RE & 5 & $6.90 \%$ \\
I & III & BE & I8 & $25.00 \%$ \\
2 & II & BE & 5 & $6.90 \%$ \\
2 & III & LE & 2 & $2.80 \%$ \\
2 & III & RE & 3 & $4.20 \%$ \\
2 & III & BE & 13 & $18.10 \%$ \\
3 & III & BE & 17 & $23.60 \%$ \\
Total & & & 72 & $100 \%$ \\
\hline
\end{tabular}

Abbreviations: $\mathrm{BE}$, both eyes; RE, right eye; LE, left eye.

defined as a positive bacterial culture in blood or CSF at less than 72 hours of age, which plays an important role in the pathogenesis of ROP, and is considered the result of intrauterine infection or vertical transmission of pathogens during delivery, which is an important cause of mortality and morbidity during the neonatal period. ${ }^{18}$ In addition, infection rates increase with decreasing birth weight and its case fatality rate is inversely related to gestational age. $^{19}$

With regard to the hemoglobin values found, the cutoff point for the diagnosis of anemia was hemoglobin $\leq$ at $13 \mathrm{~g} / \mathrm{dl}$, as recommended in the technical standard for the classification of anemia in premature infants in Peru. ${ }^{20} \mathrm{In}$ this study, newborns with anemia had 2.74 times ( $p<$ 0.05 ) more risk of ROP. Research mentions that anemia in premature infants is caused by an immature hematopoietic system, inadequate production of erythropoietin and iatrogenic blood loss. As part of their treatment, they should be given blood transfusions at some point during hospitalization according to their hemoglobin levels and clinical indications, including oxygen requirements, and are therefore more likely to develop ROP. ${ }^{21}$

Exclusive breastfeeding was shown to act as a protective factor $(\mathrm{OR}=0.016$ and $\mathrm{p}<0.05)$ (Table 3$)$. One systematic study found that providing any amount of breast milk, even if it is not exclusive, has immense clinical importance and economic benefits based on its association with a lower incidence of total ROP and severe ROP. $^{22}$ On the other hand, Zepeda-Romero established that uncontrolled oxygen supplementation is the main risk factor for severe ROP in newborns with a gestational age of $\geq 32$ weeks; ${ }^{23}$ similarly, the duration and number of hyperoxic events have been shown to increase the risk of ROP, and automated respiratory oxygen monitoring is recommended. ${ }^{24}$ In our study, preterm infants who received oxygen therapy had 10.20 times the risk of ROP ( $<$ 0.001) (Table 3); and regarding the type of oxygen therapy received, infants who received mechanical ventilation had 6.23 times the risk $(\mathrm{p}<0.001)$. Not receiving mechanical ventilation may then be a protective factor against retinopathy. ${ }^{25}$

The optimal mode of delivery for very low birthweight infants remains controversial, despite the lack of evidence of any benefit with respect to neonatal outcomes. ${ }^{26}$ Cesarean delivery is increasingly common, especially at early gestational ages. One study showed that in infants who survived after seven days of hospitalization, shortterm neonatal morbidity rates were not significant when comparing preterm infants born vaginally and those born through a cesarean section. ${ }^{26}$ In this study, those born vaginally had twice the risk $(\mathrm{OR}=2.1$ and $\mathrm{p}<0.05)$ of having ROP (Table 3), which means this is as a predictor of ROP by logistic regression analysis (Table 4).

According to Table 3, preterm infants with intraventricular hemorrhage had a 15.40 -fold increased risk $(\mathrm{p}<$ 0.01 ) of ROP, those with hyaline membrane disease had a 12.14-fold increased risk ( $<<0.001)$, bronchopulmonary dysplasia had a 3.36-fold increased risk $(p<0.001)$ of ROP, and ductus arteriosus persistence had a 4.14-fold increased risk $(\mathrm{p}<0.001)$ of ROP. On the other hand, Le C. found that other significant postnatal risk factors observed were premature infant apnea, patent ductus arteriosus and transient tachypnea of the newborn. ${ }^{27}$ Interestingly, in this study, this last variable behaved as a protective factor for ROP (OR $=0.18$ and $\mathrm{p}<0.01$ ). Necrotizing enterocolitis did not represent a significant risk factor for the onset of retinopathy, although several studies consider it as a risk factor for ROP. ${ }^{28,29}$

Finally, in multivariate analysis, gestational age $(<32$ weeks), weight $(<1500 \mathrm{~g})$, sepsis, vaginal delivery and hyaline membrane disease are presented as significant predictors of retinopathy in preterm infants (Table 4). Other studies also show that gestational age, low birth weight and hyaline membrane disease are predictors of retinopathy of prematurity. ${ }^{30,31}$ However, although in this study sepsis and vaginal delivery are considered predictors of retinopathy of prematurity, further research is needed to show the behavior of these variables in multivariate models. 
Table 3 Bivariate Analysis of Risk Factors Associated with Retinopathy in Preterm Infants

\begin{tabular}{|c|c|c|c|c|c|c|c|c|}
\hline \multirow[t]{2}{*}{ Variables } & \multirow[t]{2}{*}{ Values } & \multirow{2}{*}{$\begin{array}{c}\text { With ROP (72) } \\
\text { n (\%) }\end{array}$} & \multirow{2}{*}{$\frac{\text { No ROP (144) }}{\text { n (\%) }}$} & \multirow[t]{2}{*}{$x^{2}$} & \multirow[t]{2}{*}{ OR } & \multicolumn{2}{|c|}{$95 \% \mathrm{Cl}$} & \multirow[t]{2}{*}{$\mathbf{p}$} \\
\hline & & & & & & Low & Up & \\
\hline \multirow[t]{2}{*}{ Gestational age } & $<32$ weeks & $53(73.6)$ & $34(23.6)$ & 49.88 & 9.02 & 4.71 & 17.28 & $<0.001$ \\
\hline & $>32$ weeks & $19(26.4)$ & $110(76.4)$ & & & & & \\
\hline \multirow[t]{2}{*}{ Weight } & $<1500 \mathrm{gr}$ & $48(66.7)$ & $19(13.2)$ & 64.14 & 13.15 & 6.61 & 26.17 & $<0.001$ \\
\hline & $>1500 \mathrm{gr}$ & $24(33.3)$ & $125(86.8)$ & & & & & \\
\hline \multirow[t]{2}{*}{ Anemia } & $\mathrm{Hb}<13.0 \mathrm{mg} / \mathrm{dl}$ & $10(13.9)$ & $8(5.6)$ & 4.36 & 2.74 & 1.03 & 7.28 & $<0.05$ \\
\hline & $\mathrm{Hb}>13.0 \mathrm{mg} / \mathrm{dl}$ & $62(86.1)$ & $136(94.4)$ & & & & & \\
\hline \multirow[t]{2}{*}{ Sepsis } & Yes & $54(75)$ & $24(16.7)$ & 7.79 & 15 & 7.52 & 29.91 & $<0.001$ \\
\hline & No & $18(25)$ & $120(83.3)$ & & & & & \\
\hline \multirow[t]{2}{*}{ Breastfeeding } & Exclusive & $4(5.6)$ & $25(17.4)$ & 5.75 & 0.28 & 0.09 & 0.83 & $<0.05$ \\
\hline & Mixed & $68(94.4)$ & $119(82.6)$ & & & & & \\
\hline \multirow[t]{2}{*}{ Oxygen therapy } & Yes & $68(94.4)$ & $90(62.5)$ & 24.93 & 10.2 & 3.52 & 29.53 & $<0.001$ \\
\hline & No & $4(5.6)$ & $54(37.5)$ & & & & & \\
\hline \multirow[t]{2}{*}{ Mechanical Ventilation } & Yes & $44(61.1)$ & $29(20.1)$ & 36.01 & 6.23 & 3.33 & 11.64 & $<0.001$ \\
\hline & No & $28(38.9)$ & II5 (79.9) & & & & & \\
\hline \multirow[t]{2}{*}{ Type of delivery } & Vaginal & $34(47.2)$ & $43(29.9)$ & 6.3 & 2.1 & 1.17 & 3.77 & $<0.05$ \\
\hline & Cesarean section & $38(52.8)$ & $101(70.1)$ & & & & & \\
\hline \multirow[t]{2}{*}{ Hyaline Membrane Disease } & Yes & $60(83.3)$ & $42(29.2)$ & 56.5 & 12.14 & 5.93 & 24.85 & $<0.001$ \\
\hline & No & $12(16.7)$ & $102(70.8)$ & & & & & \\
\hline \multirow[t]{2}{*}{ Transient tachypnea of the newborn } & Yes & $4(5.6)$ & $35(24.3)$ & 11.4 & 0.18 & 0.06 & 0.53 & $<0.01$ \\
\hline & No & $68(94.4)$ & $109(75.7)$ & & & & & \\
\hline \multirow[t]{2}{*}{ Bronchopulmonary dysplasia } & Yes & II (I5.3) & $0(0)$ & 23.18 & 3.36 & 2.72 & 4.14 & $<0.001$ \\
\hline & No & $61(84.7)$ & $144(100)$ & & & & & \\
\hline \multirow[t]{2}{*}{ Necrotizing Enterocolitis } & Yes & $3(4.2)$ & $2(1.4)$ & 1.63 & 3.08 & 0.5 & 18.9 & 0.201 \\
\hline & No & $69(95.8)$ & $142(98.6)$ & & & & & \\
\hline \multirow[t]{2}{*}{ Ductus arteriosus persistence } & Yes & $17(23.6)$ & $10(6.9)$ & 12.19 & 4.14 & 1.78 & 9.61 & $<0.001$ \\
\hline & No & $55(76.4)$ & $134(93.1)$ & & & & & \\
\hline \multirow[t]{2}{*}{ Intraventricular hemorrhage } & Yes & $7(9.7)$ & I (0.7) & 1.96 & 15.4 & 1.85 & 127.74 & $<0.01$ \\
\hline & No & $65(90.3)$ & 143 (99.3) & & & & & \\
\hline
\end{tabular}

Abbreviation: $\mathrm{Hb}$, hemoglobin.

The main limitation of the present study was its retrospective design, including the observation of data from a single center, so future studies should include multiple hospitals or clinics in order to reach findings that allow for more accurate inference and generalization of results.
However, Hipólito Unanue Hospital is one of the national reference centers in Peru. Therefore, we consider that these results are still remarkable in revealing associated factors and predictors of ROP in premature infants with birth weight below 1500 gr. 
Table 4 Binary Logistic Regression of ROP Predictors

\begin{tabular}{|c|c|c|c|c|c|}
\hline \multirow[t]{2}{*}{ Variables } & \multirow[t]{2}{*}{$X^{2}$ Wald } & \multirow[t]{2}{*}{$\mathbf{O R}_{B}$} & \multicolumn{2}{|c|}{$95 \% \mathrm{Cl}$} & \multirow[t]{2}{*}{$\mathbf{p}$} \\
\hline & & & Low. & Up. & \\
\hline $\begin{array}{l}\text { Gestational age } \\
(<32 \text { weeks })\end{array}$ & 4.161 & 2.637 & 1.039 & 6.694 & $<0.05$ \\
\hline Weight (< 1500 gr.) & 10.009 & 4.377 & 1.754 & 10.923 & $<0.01$ \\
\hline Sepsis & 19.006 & 6.517 & 2.806 & 15.136 & $<0.001$ \\
\hline Vaginal birth & 8.435 & 3.748 & 1.537 & 9.14 & $<0.01$ \\
\hline $\begin{array}{l}\text { Hyaline Membrane } \\
\text { Disease }\end{array}$ & 7.838 & 3.58 & 1.466 & 8.743 & $<0.01$ \\
\hline
\end{tabular}

Abbreviation: $O R_{B}$, multivariate risk

\section{Data Sharing Statement}

The original data used to support the findings of this study are available from the corresponding authors upon request.

\section{Ethical Statement}

All procedures were performed in accordance with the 1964 Helsinki declaration and its later amendments. Due to the retrospective character of the study, written informed consent was not obtained. Patient records and data were anonymized prior to analysis.

\section{Funding}

There is no funding to report.

\section{Disclosure}

The authors report no conflicts of interest in this work.

\section{References}

1. Chawanpaiboon S, Vogel JP, Moller A-B, et al. Global, regional, and national estimates of levels of preterm birth in 2014: a systematic review and modelling analysis. Lancet Glob Health. 2019;7(1):e37e46. doi:10.1016/S2214-109X(18)30451-0

2. Howson CP, Kinney MV, McDougall L, Lawn JE. Born too soon: preterm birth matters. Reprod Health. 2013;10 Suppl 1(Supp11):S1. doi:10.1186/1742-4755-10-S1-S1

3. Kim SJ, Port AD, Swan R, Campbell JP, Chan RVP, Chiang MF. Retinopathy of prematurity: a review of risk factors and their clinical significance. Surv Ophthalmol. 2018;63(5):618-637.

4. Solebo AL, Teoh L, Rahi J. Epidemiology of blindness in children. Arch Dis Child. 2017;102(9):853-857. doi:10.1136/archdischild-2016310532

5. Carrion JZ, Fortes Filho JB, Tartarella MB, Zin A, Jornada ID Jr. Prevalence of retinopathy of prematurity in Latin America. Clin Ophthalmol. 2011;5:1687-1695.

6. Sssdp GSR, Lizárraga De Maguiña Isabel G. Factores de riesgo que inciden en la retinopatía del prematuro en el servicio de neonatología en un hospital del ministerio de salud. Rev Salud Vida Sipanense. 2016;3(1):14.
7. Zarei M, Bazvand F, Ebrahimiadib N, et al. Prevalence and risk factors of retinopathy of prematurity in Iran. J Ophthalmic Vis Res. 2019;14(3):291-298. doi:10.18502/jovr.v14i3.4785

8. Akyuz-Unsal AI, Key O, Guler D, et al. Retinopathy of prematurity risk factors: does human milk prevent retinopathy of prematurity? Turk J Pediatr. 2019;61(1):13-19. doi:10.24953/turkjped.2019.01.003

9. Freitas AM, Morschbacher R, Thorell MR, Rhoden EL. Incidence and risk factors for retinopathy of prematurity: a retrospective cohort study. Int J Retina Vitreous. 2018;4(1):20. doi:10.1186/s40942-0180125-z

10. Fierson WM. Screening examination of premature infants for ROP. Pediatrics. 2018;142(6):e20183061. doi:10.1542/peds.2018-3061

11. Capurro H, Konichezky S, Fonseca D, Caldeyro-Barcia R. A simplified method for diagnosis of gestational age in the newborn infant. J Pediatr. 1978;93(1):120-122. doi:10.1016/S0022-3476(78) 80621-0

12. Minsa P. Atencion del Recién Nacido Pre Término con Riesgo de Retinopatia del Prematuro. Norma Técnica. 2011;13.

13. Thomas K, Shah PS, Canning R, Harrison A, Lee SK, Dow KE. Retinopathy of prematurity: risk factors and variability in Canadian neonatal intensive care units. J Neonatal Perinatal Med. 2015;8 (3):207-214. doi:10.3233/NPM-15814128

14. Gunay M, Celik G, Tuten A, Karatekin G, Bardak H, Ovali F. Characteristics of severe retinopathy of prematurity in infants with birth weight above 1500 grams at a referral center in Turkey. PLoS One. 2016;11(8):e0161692. doi:10.1371/journal.pone.0161692

15. Chafloque Cervantes A, Rivera Arce GF, Aspajo Tejada E. Retinopatía de la prematuridad primera causa. Rev Peru Investig Matern Perinat. 2015;4(1):47-56.

16. Bowe T, Nyamai L, Ademola-Popoola D, et al. The current state of retinopathy of prematurity in India, Kenya, Mexico, Nigeria, Philippines, Romania, Thailand, and Venezuela. Digit J Ophthalmol. 2019;25(4):49-58. doi:10.5693/djo.01.2019.08.002

17. Diaz M, Cruzado-Sánchez D. Factores de riesgo neonatales asociados a retinopatia de la prematuridad. Rev Peru Epidemiol. 2012;16 (2):127-130.

18. Schrag SJ, Farley MM, Petit S, et al. Epidemiology of invasive early-onset neonatal sepsis, 2005 to 2014. Pediatrics. 2016;138(6): e20162013-e20162013. doi:10.1542/peds.2016-2013

19. Jiang S, Yang Z, Shan R, et al. Neonatal outcomes following culture-negative late-onset sepsis among preterm infants. Pediatr Infect Dis J. 2020;39(3):232-238. doi:10.1097/INF.000000 0000002558

20. Perú. MINSA. Manejo Terapéutico y preventivo de la anemia en niños, adolescentes, mujeres gestantes y puerperas. Norma Técnica. $2017 ; 12$.

21. Lundgren P, Hellgren G, Pivodic A, Savman K, Smith LEH, Hellstrom A. Erythropoietin serum levels, versus anaemia as risk factors for severe retinopathy of prematurity. Pediatr Res. 2019;86 (2):276-282. doi:10.1038/s41390-018-0186-6

22. Bharwani SK, Green BF, Pezzullo JC, Bharwani SS, Bharwani SS, Dhanireddy R. Systematic review and meta-analysis of human milk intake and retinopathy of prematurity: a significant update. J Perinatol. 2016;36(11):913-920. doi:10.1038/jp.2016.98

23. Zepeda-Romero LC, Lundgren P, Gutierrez-Padilla JA, et al. Oxygen monitoring reduces the risk for retinopathy of prematurity in a Mexican population. Neonatology. 2016;110(2):135-140. doi:10.1159/000445040

24. Kaufman DA, Zanelli SA, Gurka MJ, Davis M, Richards CP, Walsh BK. Time outside targeted oxygen saturation range and retinopathy of prematurity. Early Hum Dev. 2014;90:S35-S40. doi:10.1016/S0378-3782(14)50010-2

25. Yang MC, Hsiao HF, Tseng HL, Chiu YW, Weng YH. Aerosol therapy in relation to retinopathy of prematurity in mechanically ventilated preterm infants. BMC Pulm Med. 2019;19(1):145. doi:10.1186/s12890-019-0912-9 
26. Varga P, Berecz B, Gasparics Á, et al. Morbidity and mortality trends in very-very low birth weight premature infants in light of recent changes in obstetric care. Eur J Obstet Gynecol Reprod Biol. 2017;211:134-139. doi:10.1016/j.ejogrb.2017.01.051

27. Le C, Basani LB, Zurakowski D, Ayyala RS, Agraharam SG. Retinopathy of prematurity: incidence, prevalence, risk factors, and outcomes at a tertiary care center in Telangana. J Clin Ophthalmol Res. 2016;4(3):119. doi:10.4103/2320-3897.190785

28. Gebesce A, Uslu H, Keles E, et al. Retinopathy of prematurity: incidence, risk factors, and evaluation of screening criteria. Turk J Med Sci. 2016;46(2):315-320. doi:10.3906/sag-1407-127
29. Siswanto JE, Ronoatmodjo S, Adisasmita A, Soemantri A, Sitorus RS, Sauer PJJ. Risk factors for the development and progression of retinopathy of prematurity in preterm infants in Indonesia. J Neonatal Perinatal Med. 2019.

30. Sathar A, Girijadevi AS, Pillai RK. Risk factors of retinopathy of prematurity in a tertiary care hospital in South India. Clin Epidemiol Glob Health. 2018;6(1):44 49. doi:10.1016/j.cegh.2017.02.002

31. Ludwig CA, Chen TA, Hernandez-Boussard T, Moshfeghi AA, Moshfeghi DM. The epidemiology of retinopathy of prematurity in the United States. Ophthalmic Surg Lasers Imaging Retina. 2017;48 (7):553-562. doi:10.3928/23258160-20170630-06
Clinical Ophthalmology

\section{Publish your work in this journal}

Clinical Ophthalmology is an international, peer-reviewed journal covering all subspecialties within ophthalmology. Key topics include: Optometry; Visual science; Pharmacology and drug therapy in eye diseases; Basic Sciences; Primary and Secondary eye care; Patient Safety and Quality of Care Improvements. This journal is indexed on PubMed

Submit your manuscript here: https://www.dovepress.com/clinical-ophthalmology-journal
Dovepress

Central and CAS, and is the official journal of The Society of Clinical Ophthalmology (SCO). The manuscript management system is completely online and includes a very quick and fair peer-review system, which is all easy to use. Visit http://www.dovepress.com/ testimonials.php to read real quotes from published authors. 